\title{
Correlation of platelet indices with severity of pre-eclampsia: a prospective study from central India
}

\author{
Ruchika Dhakre, Gurpreet Kaur Nandmer*, Rekha Sapkal
}

\begin{abstract}
Department of Obstetrics and Gynecology, People's College of Medical Science and Research Centre, Bhopal,
\end{abstract} Madhya Pradesh, India

Received: 12 March 2018

Accepted: 22 March 2018

*Correspondence:

Dr. Gurpreet Kaur Nandmer,

E-mail: kaurgauri2@yahoo.co.in

Copyright: () the author(s), publisher and licensee Medip Academy. This is an open-access article distributed under the terms of the Creative Commons Attribution Non-Commercial License, which permits unrestricted non-commercial use, distribution, and reproduction in any medium, provided the original work is properly cited.

\begin{abstract}
Background: Although it is generally accepted that the haemoglobin concentration decreases and white cell count increases during normal pregnancy, there is less accord regarding changes in platelet indices. Present study was performed to know the relation of platelet indices with normal pregnancy, preeclampsia and severity of pre-eclampsia. Methods: Hundred pregnant women were studied at Department of Obstetrics and Gynaecology, PCMS and RC, Bhopal after dividing them in two Group $\mathrm{N}(\mathrm{n}=50$, normal pregnant women) and Group $\mathrm{P}(\mathrm{n}=50$, pre-eclampsia patient). Platelet indices including platelet count mean platelet volume and platelet distribution width were estimated in all the patients. Data were analyzed using IBM SPSS ver. 20 software. Level of significance was assessed at $5 \%$.

Results: In Group P [34 (68\%)] and Group N [21 (42\%)] most of the patients had platelet count of <2 lac respectively. Whereas Group P, $16(32 \%)$ patients had thrombocytopenia (platelet count between 50-1.5 lac) where as in Group N, none of the patients had lower platelet count. Most of the patients (55\%) in study cohort had PDW of 15 $\mathrm{fl}$ out of that half of the patients in Group N had PWD as $15 \mathrm{fl}$ whereas in Group P 60\% had PDW value as $15 \mathrm{fl}$. Out of 50 preeclampsia patients $24(48 \%)$ were of severe type, out of which $54 \%$ had platelet count $<1.5 \mathrm{lac}, 83 \%$ had PDW as 15-16fl, and 54\% had MPV in the range of 10-11 fl.

Conclusions: Platelet count decreases while MPV and PDW increase as pregnancy advances, and these changes are more pronounced in preeclampsia than normotensive pregnancy.
\end{abstract}

Keywords: MPV, PDW, Platelet count, Pregnancy induced hypertension, Thrombocytopenia

\section{INTRODUCTION}

Preeclampsia is a pregnancy-specific multisystem disorder characterized by abnormal vascular response to placentation which is associated with increased systemic vascular resistance, enhanced platelet aggregation, activation of the coagulation system, and endothelial cell dysfunction with resultant reduced organ perfusion. Despite extensive research, the cause of preeclampsia remains elusive. ${ }^{1,2}$

Current criteria for a diagnosis of preeclampsia require the presence of de novo hypertension (blood pressure of $\geq 140 / 90 \mathrm{mmHg}$ ), with proteinuria or any of the other multisystem abnormalities, with onset after the $20^{\text {th }}$ week of gestation. ${ }^{3,4}$

Platelet indices [platelet count, mean platelet volume (MPV) and platelet distribution width (PDW)] constitute part of the data detectable by complete blood count (CBC) test. Applicability of these indices for the clinical and pathophysiological understanding of vascular diseases, including preeclampsia, has been investigated but their value has not yet been fully substantiated. ${ }^{5} \mathrm{~A}$ decreasing platelet count is observed during the progression of preeclampsia, and is suggested to be a 
characteristic of worsening preeclampsia. ${ }^{6}$ This platelet count decline returns rapidly to its normal range after delivery. It has also been noted that MPV increases during pregnancy and is higher in women with preeclampsia. Increased MPV occurs before onset of preeclampsia symptoms. Therefore, it may be a valuable marker for development of preeclampsia. ${ }^{5}$ Furthermore, it has been suggested that PDW can be a practical tool to evaluate activation of coagulation or thrombocytosisrelated disease. ${ }^{7}$

The aim of this study was, therefore, to assess whether changes in platelet indices, detectable on CBC during pregnancy could be used as markers for prediction of development of preeclampsia.

\section{METHODS}

A prospective case-control study was done on 100 women at Department of Obstetrics and Gynaecology, PCMS and RC, Bhopal. Study cohort was subdivided in two Group $\mathrm{N}$ ( $\mathrm{n}=50$, normal pregnant women) and Group P ( $\mathrm{n}=50$, pre-eclampsia patient).

Institutional Ethics committee approval and a written informed consent were obtained from each patient before starting the study. All patients presenting with preeclampsia, mild pre-eclampsia (as per ACOG guidelines; BP $\geq 140 / 90 \mathrm{mmHg}$ at 2 intervals 4 hours apart with or without significant proteinuria) and severe pre-eclampsia (As per ACOG guidelines, BP $\geq 160 / 110 \mathrm{mmHg}$ and proteinuria $>5 \mathrm{gm} / 24$ hours) were included.

Post-delivery patients, patient with coagulation disorders like Idiopathic thrombocytopenia, sickle cell disease, viral hepatitis, cholestatic jaundice, acute fatty liver, malaria, drug induced jaundice dengue and chronic hypertension were excluded.

Blood pressure and proteinuria were estimated in all the subjects. Data on presence of nausea, vomiting, headache, urine output less than $400 \mathrm{ml} / 24 \mathrm{hrs}$, haemogram, hypoproteinaemia, raised liver enzymes, deranged KFT, presence of haemolysis and Platelet indices (platelet count, mean platelet volume, platelet distribution width) were also recorded.

All the data was analyzed using IBM SPSS ver. 20 software. Frequency distribution and cross tabulation was used to prepare tables. Quantitative data was analyzed using student $\mathrm{t}$ test while categorical data was analyzed using Chi square test. Level of significance was assessed at $5 \%$.

\section{RESULTS}

Mean age of study cohort was $24.45 \pm 4.23$ years. Most of the subjects in Group P [44 (88\%)] and Group N [42 $(84 \%)$ ] belong to age group of $21-25$ years.
Table 1: Comparing platelet indices and platelet distribution width between normal pregnancy and preeclampsia patients.

\begin{tabular}{|c|c|c|c|}
\hline Platelet indices & & Group N & Group P \\
\hline \multirow{7}{*}{ Platelet count } & $<50000$ & $0(0)$ & $2(4)$ \\
\hline & $\begin{array}{l}51000-1 \\
\text { Lakhs }\end{array}$ & $0(0)$ & $5(10)$ \\
\hline & $\begin{array}{l}1.1-1.5 \\
\text { Lakhs }\end{array}$ & $0(0)$ & $9(18)$ \\
\hline & $\begin{array}{l}1.51-2 \\
\text { Lakhs }\end{array}$ & $24(48)$ & $18(36)$ \\
\hline & $\begin{array}{l}2.1-2.5 \\
\text { Lakhs }\end{array}$ & $13(26)$ & $10(20)$ \\
\hline & $\begin{array}{l}2.51-3 \\
\text { Lakhs }\end{array}$ & $7(14)$ & $3(6)$ \\
\hline & $\begin{array}{l}>3 \\
\text { Lakhs }\end{array}$ & $6(12)$ & $3(6)$ \\
\hline \multirow{8}{*}{$\begin{array}{l}\text { Platelet } \\
\text { distribution } \\
\text { width (fl) }\end{array}$} & 10 & $3(6)$ & $0(0)$ \\
\hline & 11 & $6(12)$ & $1(2)$ \\
\hline & 12 & $3(6)$ & $0(0)$ \\
\hline & 13 & $0(0)$ & $0(0)$ \\
\hline & 14 & $8(16)$ & $5(10)$ \\
\hline & 15 & $25(50)$ & $30(60)$ \\
\hline & 16 & $5(10)$ & $13(26)$ \\
\hline & 17 & $0(0)$ & $1(2)$ \\
\hline
\end{tabular}

Data is expressed as no of patients (percentage), Group $\mathrm{N}$ $(\mathrm{n}=50$, normal pregnant women) and Group $\mathrm{P}(\mathrm{n}=50$, pre-eclampsia patient). In pre-eclampsia $32 \%$ had platelet count between 50 thousand to $1.5 \mathrm{lac}$. No normal case had such low value. $68 \%$ of pre-eclampsia and $42 \%$ of normal patients had count less than 2 lac. Maximum (55\%) had PDW as $15 \mathrm{fl} .50 \%$ of normal patients had PDW value as $15 \mathrm{fl}$. However, $60 \%$ of pre-eclampsia had PDW value as $15 \mathrm{fl}$.

Table 2: Showing platelet indices with severity of preeclampsia.

\begin{tabular}{|c|c|c|}
\hline \multicolumn{2}{|c|}{ Platelet indices } & $\begin{array}{l}\text { Severe preeclampsia } \\
(\mathbf{n}=24)\end{array}$ \\
\hline \multirow{7}{*}{$\begin{array}{l}\text { Platelet } \\
\text { count }\end{array}$} & $<50000$ & 3 \\
\hline & 51000-1 Lakhs & 5 \\
\hline & 1.1-1.5 Lakhs & 5 \\
\hline & 1.51-2 Lakhs & 3 \\
\hline & 2.1-2.5 Lakhs & 5 \\
\hline & 2.51-3 Lakhs & 2 \\
\hline & >3 Lakhs & 1 \\
\hline \multirow{4}{*}{$\begin{array}{l}\text { Platelet } \\
\text { distribution } \\
\text { width (fl) }\end{array}$} & 14 & 3 \\
\hline & 15 & 15 \\
\hline & 16 & 5 \\
\hline & 17 & 1 \\
\hline \multirow{6}{*}{ MPV } & 9 & 5 \\
\hline & 10 & 8 \\
\hline & 11 & 5 \\
\hline & 12 & 2 \\
\hline & 13 & 3 \\
\hline & $>13$ & 1 \\
\hline
\end{tabular}




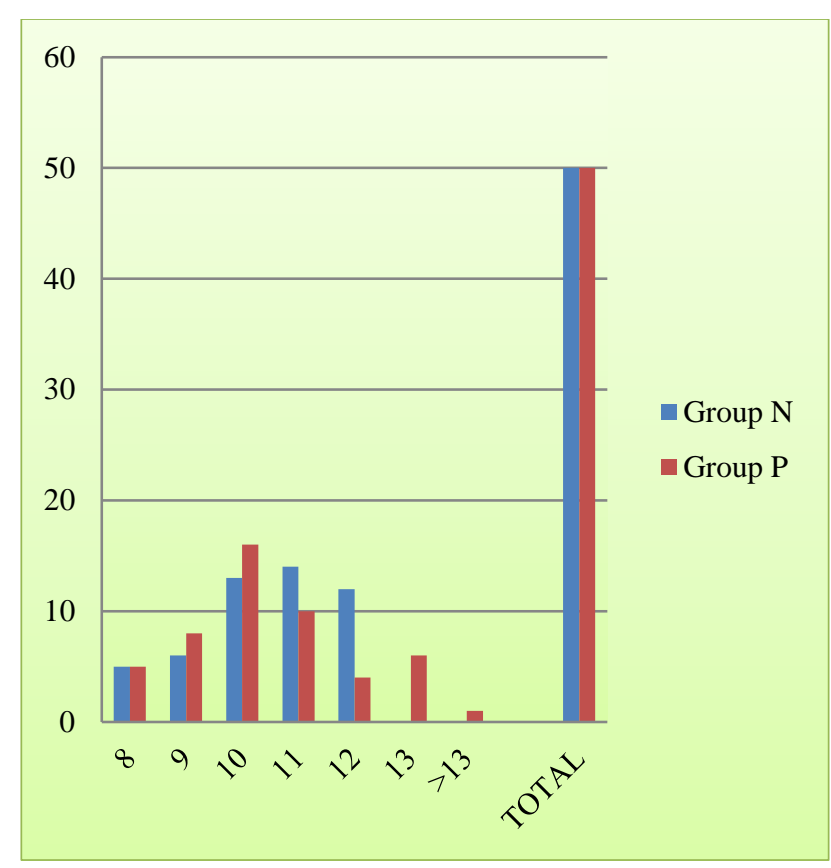

Figure 1: Mean platelet volume between groups.

Data is expressed as no of patients (percentage), MPV; mean platelet volume, 24 cases of severe pre-eclampsia were analysed for platelet count. Out of which maximum (54\%) had platelet count $<1.5$ lac and rest had normal count. $83 \%$ of severe pre-eclampsia had PDW as $15-16$ fl. $54 \%$ Severe Pre-eclampsia had MPV range as 10-11fl.

\section{DISCUSSION}

Preeclampsia continues to be a major cause of maternal and fatal morbidity and mortality, as it is associated with a high risk of IUGR, preterm delivery, placental abruption etc. ${ }^{8}$ Furthermore, there is a concern about the long-term consequences of preeclampsia, as women who experience this disorder represent a high-risk group for subsequent premature cardiovascular, cerebrovascular, peripheral arterial diseases and other chronic illnesses later in life. ${ }^{9,10}$

Present prospective observational case control study included 100 subjects, out of which 50 were controls and 50 were having PIH. In this study an attempt was made to assess the role of platelet indices in assessment of severity of preeclampsia. In developing countries like India PIH has been attributed to be a significant cause of maternal and perinatal morbidity and mortality. ${ }^{11}$

In present study mean age of patients was $24.45 \pm 4.23$ years, which is comparable with the studies done by Prakash et al reported mean age of $24.75 \pm 3.360$ years respectively, however study done by Onisai et al observed higher mean age compared to present study. ${ }^{12,13}$

In present study mean platelet count in pre-eclampsia was $1.88 \mathrm{Lakhs} / \mathrm{cu} \mathrm{mm}$ which is comparable to studies by Mohapatra et al showing $1.8 \mathrm{Lakhs} / \mathrm{cu} \mathrm{mm} .{ }^{14}$ Present study results are in agreement with those reported by other researchers. ${ }^{6,15}$

Study done by Siddiqui et al has stated that approximately $50 \%$ of preeclampsia cases will develop thrombocytopenia, similar to that in present study $32 \%$ of the preeclampsia cases were having thrombocytopenia. ${ }^{16}$ Thrombocytopenia in PIH is mostly caused due to increase consumption of platelet may be due to adherence of platelet at the site of damaged vascular endothelium.

In present study we have observed an increase in MPV and PDW values from normotensive pregnant women to pre-eclampsia patients which is in agreement with other studies. In the present study MPV was 9.26 in preeclampsia which is comparable with Giles et al who observed MPV of 9.9. ${ }^{17}$ In the present study PDW was 15.26 in preeclampsia which is comparable with Giles et al who observed PDW of $16 .{ }^{17}$ Similar results were revealed in a study done by Siddiqui et al on 125 cases. ${ }^{16}$

MPV showed gradual increase in preeclampsia patients as compared to normotensive subjects. Inter group analysis done by Nooh et al revealed that changes in MPV values in PE-developing women (with and without severe features) were statistically more significant than normotensive pregnant women and this change was noted to start from the $24^{\text {th }}$ gestational week up to time of delivery $(\mathrm{p}=0.003)^{8}{ }^{8}$

Furthermore, Nooh et al also reported that in the PE groups, onset of diagnosis was at 30-32 weeks gestation, and significant MPV increase was noted to precede development of PE by approximately 2-8 weeks. Dundar et al, in a previous large longitudinal study suggested that increase of MPV may precede development of PE symptoms by approximately 4.6 weeks (range 2.8-5.9 weeks). ${ }^{5}$ Based on present study findings we can consider MPV as a possible modest marker for prediction of severity of hypertension. This is in agreement with what was concluded by other investigators. ${ }^{6,10}$

Similarly, PDW value also showed gradual increase in preeclampsia patients as compared to normotensive subjects. Our results are in agreement with those of previous studies making PDW the best potential marker for prediction of severity of hypertension. ${ }^{6,18}$ However, Yang et al identified a PDW value of $>13.5$ as the optimal cut-off level for the prediction of preeclampsia severity. ${ }^{6}$ Similarly, Freitas et al identified a PDW value of $>18.3$ as the optimal cut-off level for the prediction of PE. ${ }^{18}$

Conflicting results have been published regarding changes in platelet indices in normotensive pregnancies and preeclampsia. Some investigators found no difference in values of these indices between preeclampsia and controls, whereas others demonstrated lower platelet count and higher MPV and PDW in preeclampsia. ${ }^{19,20,5,6,7,21}$ It is suggested that the major 
reason for the inconsistency between these studies is probably the method of measurement of these platelet indices. Measurements performed in EDTA change in a time-dependent manner. Also, different systems used in measurement can yield different results, and this difference may reach up to $40 \% .^{19}$

In present study, out of 50 preeclampsia patients 24 $(48 \%)$ were of severe type, out of which $54 \%$ had platelet count $<1.5$ lac, $83 \%$ had PDW as $15-16 \mathrm{fl}$, and $54 \%$ had MPV in the range of 10-11fl. In agreement to present study Annam et al also reported that The MPV and PDW values were elevated proportionally with the severity of pre-eclampsia when compared with the control group. ${ }^{22}$ Severity of PIH and thrombocytopenia observed are closely correlated which indicates that thrombocytopenia is directly proportional to the severity of PIH. Similar reported were presented by study done by Mohapatra et al, Walker et al and Taylor et al. ${ }^{14,23,24}$

\section{CONCLUSION}

To conclude this study provides evidence that platelet count decreases while MPV and PDW increase as pregnancy advances, and these changes are more pronounced in preeclampsia than normotensive pregnancy. To conclude present study recommends monitoring platelet count, MPV and PDW which are simple, economical and rapid investigations to monitor the progress of PIH. We also found an association between platelet indices and severity of preeclampsia. The study showed the platelet indices as the most consistent and reliable investigation for early detection of $\mathrm{PIH}$ cases. Hence platelet indices can also be used as a prognostic marker.

\section{Funding: No funding sources}

Conflict of interest: None declared

Ethical approval: The study was approved by the Institutional Ethics Committee

\section{REFERENCES}

1. Ananth CV, Keyes KM, Wapner RJ. Preeclampsia rates in the United States, 1980-2010: age-periodcohort analysis. BMJ. 2013;347:f6564.

2. Ness RB, Sibai BM. Shared and disparate components of the pathophysiologies of fetal growth restriction and preeclampsia. Am J Obstet Gynecol. 2006;195:40-9.

3. Sibai BM. Evaluation and management of severe preeclampsia before 34 weeks' gestation. Am J Obstet Gynecol. 2011;205:191-8.

4. Sibai BM, Dekker G, Kupferminc M. Preeclampsia. Lancet. 2005;365:785-99.

5. Dunda O, Yoruk, P, Tutuncu L, et al. Longitudinal study of platelet size changes in gestation and predictive power of elevated MPV in development of preeclampsia. Prenatal Diag. 2008;28:1052-6.
6. Yang SW, Cho SH, Kwon HS. Significance of the platelet distribution width as a severity marker for the development of preeclampsia. Eu J Obstet Gynecol Reprod Biol. 2014;175:107-11.

7. Vagdatl E, Gounari E, Lazaridou E. Platelet distribution width: a simple, practical and specific marker of activation of coagulation. Hippokratia. 2010;14:28-32.

8. Nooh AM, Abdeldayem HM. Changes in platelet indices during pregnancy as potential markers for prediction of preeclampsia development. Open $\mathbf{J}$ Obstet Gynecol. 2015;5:703-12.

9. Simeone S, Lojo C, Garcia-Esteve L. Psychological impact of first-trimester prevention for preeclampsia on anxiety. Prenatal Diag. 2015;35:60-4.

10. Missfelder-Lobos H, Teran E, Lees C. Platelet changes and subsequent development of preeclampsia and fetal growth restriction in women with abnormal uterine artery doppler screening. Ultrasound Obstet Gynecol. 2002;19:443-8.

11. Vigil D, Gracia U. Pregnancy complicated by preeclampsia eclampsia with HELLP syndrome. Elsevier; 2001;72 (1):17-23.

12. Prakash J, Pandey LK, Singh AK, Kar B. Hypertension in pregnancy: hospital based study. $\mathbf{J}$ Assoc Phy India. 2006;54:273-8.

13. Onisai M, Vladareaner AM, Bumbea H, Clorascu M, Pop C, Andrei C, et al. A study of haematological picture and of platelet function in preeclampsiareport of a series of cases. J Clin Med. 2009;4:326-7.

14. Mohapatra S, Pradhan BB, Satpathy UK, Mohanty A, Pattnaik JR. Platelet estimation: its prognostic value in pregnancy induced hypertension. Ind $\mathbf{J}$ Physiol Pharmacol. 2007;51(2):160-4.

15. Dadhich S, Agrawal S, Soni M. Predictive value of platelet indices in development of preeclampsia. Journal of SAFOG with DVD. 2012;4:17-21.

16. Siddiqui RP, Chandrakar K, Varma R, Shrivastava S. Study on platelet indices in pregnancy induced hypertension. J Evidence based Med Healthcare. 2015;2 (44):8035-40.

17. Giles C. The platelet count and mean platelet volume. Br J Haematol. 1981;48(1):31-7.

18. Freitas LG, Alpoim PN, Komatsuzaki F. Preeclampsia: are platelet count and indices useful for its prognostic? Hematol. 2013;18:360-4.

19. Ceyhan T, Beyan C, Baser I. The effect of preeclampsia on complete blood count, platelet count and mean platelet volume. Ann Hematol. 2006;85:320-2.

20. Makuyana D, Mahomed K, Shukusho FD. Liver and kidney function tests in normal and pre-eclamptic gestation: a comparison with non-gestational reference values. Central Afr J Med. 2002;48:55-9.

21. Järemo P, Lindahl, TL, Lennmarken, C. The use of platelet density and volume measurements to estimatethe severity of preeclampsia. Eu J Clin Investigation. 2000;30:1113-8.

22. Annam V, Srinivasa K, Yatnatti SK, Suresh DR. Evaluation of platelet indices and platelet counts and 
their significance in pre-eclampsia and eclampsia. Int J Biol Med Res. 2011;2(1):425-8.

23. Walker JJ, Cameron AD, Bjornsson S, Singer CRJ, Fraser C. Can platelet volume predict progressive hypertensive disease in pregnancy? Am J Obstet Gynaecol. 1989;161:676-9.
24. Taylor DJ, Lind T. Haematological changes during pregnancy: Iron induced macrocytois. $\mathrm{Br} \mathrm{J}$ Obstet Gynaecol. 1976;83:760-7.

Cite this article as: Dhakre R, Nandmer GK, Sapkal R. Correlation of platelet indices with severity of preeclampsia: a prospective study from central India. Int J Reprod Contracept Obstet Gynecol 2018;7:141620. 